\title{
The ethics of human cadaver organ transplantation: a biologist's viewpoint
}

\author{
H E Emson University Hospital, Saskatoon, Canada
}

\section{Author's abstract}

The rights of the various individuals involved in decisionmaking in cadaver organ donation are considered, and there is discussion of the relation of human cadavers to the planetary biomass. I conclude that the rights of the potential recipient should outweigh those of the other parties concerned and that education and legislation should recognise and promote this.

When the grafting of human cadaver organs became practical, from the body of a deceased to that of a living individual, the rights of the various people involved became a matter of concern; who had, or should have, the right to authorise or deny such organ transfer? The persons involved have been identified as the deceased, the 'owner' of the organ; the immediate family of the deceased; the potential recipient; and the community as a whole, perhaps as representing potential recipients. I submit that in addition to these established positions of interest it is also relevant to consider the issue in relation to what may be described as the planetary biomass, which is not a person and cannot in a conventional sense have an interest, but of which the body of a potential donor is a part, and to consider a 'biological ethic' as well.

In English law and those jurisdictions derived from it, there has never been established a concept of property in a dead body. Various persons have been defined as having legal duties in relation to its care, treatment and disposal, and these duties carry with them certain privileges of choice, but until organ grafting became practical all these were directed only towards ensuring disposal of the body which was hygienic and decent in the observances of contemporary society; there was no other relevant consideration. When cadaver organ transplantation became a routine procedure, means of facilitating donation were developed by giving to an individual limited authority to dispose of his or her body, or its parts, using recorded wishes on donor cards and

\section{Key words}

Cadaver; organ; donation; recipient; biological; biomass; recycle. similar devices. These were ethically unidirectional, designed to facilitate donation when it was desired, but not to prevent it if that was the deceased's wish. Organ donation was perceived to be a good which should legally be made easier of achievement.

The reason why a person should have the right to determine the disposition of his or her organs after death was rarely considered or stated; it is at least challengeable. If our ethic places primary value upon the integrity of the individual, with establishment of autonomy as a good, the deceased is not a person and there seems to be no prima facie ethical reason why a living person should have control over his or her subsequently dead body. Whatever the person consists of, and wherever we believe that goes at the time of death, it is not present in the cadaver. In law the body is not considered to be property, and it is not in this sense bequeathable.

The immediate family has responsibilities for the care and disposal of the cadaver within the customary practices of society; should these be extended to a right to determine donation of organs? The customs and rituals following death have as their main reason the acceptance of the division of body and spirit, which have up to this time been indivisible. Acts performed upon the cadaver immediately following death are commonly felt, emotionally, to be acts upon a still sentient individual, as I have experienced when requesting permission for autopsy: 'Oh, doctor, hasn't he suffered enough already?' Kational discussion, if it is felt appropriate at this point, will establish that there is no belief that a cadaver can or does suffer pain, but acceptance of the fact of death takes time, and the respect with which the cadaver is treated is that appropriate in many ways to a still-living individual. Even when the fact of death is accepted, respect is still accorded to human remains as those of one who was a person, and this is quite separate from any idea of literal corporeal resurrection. Some religions, notably the Jewish, place such importance upon the respect to be paid to a human cadaver as to greatly limit or prohibit the performance of autopsy.

These beliefs and attitudes are firmly ingrained in our society and it would be neither right nor possible arbitrarily to override them. Much of their basis rests upon millions of years of experience, a part of which 
is that death is invariably followed by decomposition and dissolution. It is not possible quickly to replace this race memory in the very few years of our rationally acquired knowledge that the cadaver can be used in other ways; this knowledge will be incorporated into our society's common parlance, and be reflected in our behaviour and our beliefs, but it will take time. Respectful rites paid to the cadaver which once was human are as old as humanity itself and, depending upon how one defines humanity in anthropological terms, possibly much older; one of the things that distinguishes humanity at its earliest points of evolutionary emergence is evidence of funeral observances. The idea that the cadaver which is no longer of value to its erstwhile occupant, can yet be of vital use to another still-living person, will have to be reconciled with this form of belief and practice also. If our society continues to believe that cadaver organ donation is a good and should be facilitated, then this can be promoted by education and by policies which also take account of beliefs and emotions, however apparently illogical these may be.

In a strictly utilitarian ethic the rights of the potential recipient would be pre-eminent, and indeed there could scarcely be a better and simpler case study. An organ which in the normal and irreversible course of nature is destined for rapid decomposition, is for a living human recipient life-saving; what are the rights of anyone else? But as I have said, ideas and systems for dealing with death that have evolved over millions of years are not so quickly and easily replaced by the sheer force of rational argument. Another problem is that the identity of the potential recipient is rarely known, because of the necessity for tissue-matching and compatibility tests, and there is always less ethical force in an unnamed potential person than in a living identifiable one. The recipient is in the position of an 'innocent other', not primarily involved in the problem but vitally affected by its outcome. The recipient's interest is both in survival, life as an absolute value, and in the increased quality of life following transplantation as compared with other treatments such as dialysis.

Society, as representing the innocent others who will benefit from organ donation, has an interest in these rights; society also has a utilitarian interest because organ transplantation represents a considerable decrease in its financial load, when compared with other forms of maintenance treatment.

Finally, there is a point of view which does not seem to have been well or frequently expressed, which I can term biological. To the biologist there can be no concept of ownership of a physical body; our bodies are part of a total pool of elements and molecules which is the biomass of our planet, and which interacts with its inorganic mass to some extent. We acquire our bodies by anabolic synthesis from this pool, during their growth, and during their lives we exchange their components, their elements and molecules, with the pool. The individual body has the character of a stream, having the same continuing gross appearance but whose constituent parts are continually changing. After death, when whatever it is that makes the individual has departed, the body which he or she has used must inevitably return to the pool, to come up again as wheat or roses. Were it not so we never could have existed, because all the available constituents would have remained forever locked up in the incorruptible bodies of the first generation of life. The individual body can be thought of as 'on loan from' the biomass, but to term this a loan is not strictly accurate; a loan is a volitional agreement with an obligation to return. The acceptance of individual life is not voluntary, though continuing in it may be, and the ultimate obligation to return the individual body is neither permanently evadable nor revocable.

An ethic has no choice but to accept these biological inevitabilities; it cannot ignore facts. Our humancentred ethic assumes that the biomass is there to be manipulated for what humans construe as their good, and it is very slowly and reluctantly being borne in upon humanity, that in many ways human beings are an inseparable part of the biomass and ultimately governed by its laws, not it by theirs. In terms of a 'biological ethic' organ transplantation is an incident of neutral value and no permanent relevance; re-entry of material into the pool is delayed but not prevented A living human being is benefited by the process, an 8 the only detriment, if such it be, is to potential organisms which will use the same constituents, but whose utilisation of them is delayed.

The individual by whom the constituents of a body have been used through life, has not the ability to determine their ultimate disposition after he or she has done with them (short of the extremes of permanent cryogenic preservation or firing them off into space). Should he or she have a right to determine or modify the circumstances of their return to the pool? Should the immediate relatives have that right? The decision of society until very recently was that there should be these rights, but society is now faced with alternatives which did not exist before. In my opinion the rights of the potential recipient, as represented by society, to the chance of either life itself or an improved quality of life, should outweigh those of the previous user of the cadaver, or his/her relatives, to deny these rights in the name of funeral observances, respect to the previously existing individual, or anything else. In setting the value of an existing human being, albeit one who may not be individually identifiable, above those of potential wheat or roses, or of a potential human being further down the path of recycled elements, or of rituals and respect for a dead person, the 'biological ethic' is in accord with the utilitarian and deontological approaches to cadaver organ transplantation. Having finished with the use of my body, the best use to which it can be put is to promote the well-being of an existing human being; the next best, is promptly to return it to the pool. 
The means by which society provides for these rights will be geared to society's acceptance of them, and as I said above, I do not think this can or should be an arbitrary overriding of beliefs, even if they are held by a minority. One of the problems of such situations is that it is only the holders of extreme beliefs who commonly express them; the majority of society is generally inarticulate, and we have very poor means of assessing its opinions. Some societies very close to ours have instituted the mandatory request for organ donation, laying the onus of asking upon the medical attendants in the final illness. The form of the request is very important; one which implies that it is normal to donate, that there will be no objection, will secure more positive responses than one which is neutral or assumes the opposite. Other societies close to ours have extended the concept even further, to mandatory availability of organs suitable for transplantation, without request; my own ethical belief accords with this attitude, but I doubt whether it would be possible to force this upon contemporary British or Canadian society. I do think that society's readiness to accept such ideas is consistently underestimated, but this is a type of nettle which no democratically elected Government is keen to grasp; vocal minorities carry more political weight than do inarticulate majorities. Certainly a defined, consistent and funded policy of eaucauon would move society rapidly towards such acceptance, particularly when the simple matter is emphasised, that the procedures necessary for organ donation neither disfigure a body for contemporary funeral rites, nor significantly delay its release for them.

To a scientist it is attractive to postulate 'rights' of the biomass, but most of man's thinking has set him apart from and above the rest of creation and we are still arguing about the rights of the higher mammalia. Man does and will manipulate the biomass to his own ends and is learning very slowly that such manipulations frequently result in consequences which are unforeseen in nature and extent, and often deleterious; this applies to organ transplantation. In considering the human body during life, and the cadaver after death, we should take into account the totality of which it is a part. One reason for doing this is that other human beings are also part of this totality, and what we do, as at Chernobyl, may affect them. Whatever ethical value we place upon the non-human constituents of the biomass we cannot ignore them because we are part of the totality, and biologically we are indeed all members one of another.

H E Emson MA MD FRC P $(C)$ is Professor and Head, Department of Pathology, College of Medicine, I 'niversity of Saskatchewan, Saskatoon, Saskatchewan, Canada S7N OXO.

\section{News and notes}

\section{Medical decision-making conference}

The second conference of the European Society for Medical Decision-making will be held in Copenhagen from 1st-4th June 1988. For further information contact Jorgen Hilden or Annelise Nielsen, University of Copenhagen, Panum Institute, Blegdamsvej 3, DK-2200 Copenhagen N, Denmark.

Papers (both theoretical and applied) are invited on any aspect(s) of medical decision-making such as clinical decision-making per se; clinical research and decision-making; regional variations in medical practice; quality of life and utility assessment; resource allocation and medical decision-making; clinical behaviour; ethics and choice in medicine; decision aspects of clinical research methodology; computational and graphical tools; health policy and medical decision-making; and other relevant topics in medical decision-making.

Those wishing to offer a paper should contact Jorgen Hilden or Annelise Nielsen, preferably with an indication of topic. 